\title{
Hydraulic analysis of functioning of the drainage channel with increased retention capacity
}

\author{
Kamil Pochwat ${ }^{1, *}$ \\ ${ }^{1}$ Department of Infrastructure and Sustainable Development, Faculty of Civil and Environmental \\ Engineering and Architecture, Rzeszow University of Technology, al. Powstańców Warszawy 6, \\ 35-959 Rzeszów, Poland
}

\begin{abstract}
Hydraulic overload of networks and its related objects is a problem that is more and more common in drainage systems. The most popular way to prevent it from its occurring is to increase the storage capacity of the system. At present, there are numerous solutions allowing to increase retention in drainage systems, with the selection of the most beneficial one being dependent on numerous factors; it must also be preceded by a technical and financial analysis. Financial analysis is of particular importance here, since due to significant dimensions and complicated structure, these objects require high investment outlays for its construction. As a consequence, it is a priority to undertake actions aimed at developing such solutions that will allow for significant increases of retention in the drainage system, and cost reductions at the same time. One of such solutions is the Underground tank for combined sewage and stormwater that is now patent-pending. The application of this solution allows to multiply retention capacity of the drainage system, without the necessity of modernizing the existing sewer system. This paper presents the application potential of the subject method for increasing sewer retention, along with its hydraulic function analysis. The research carried out and presented was based on the analysis of individual phases of functioning of the subject solution.
\end{abstract}

\section{Introduction}

A phenomenon more and more commonly encountered in traditional drainage systems involves hydraulic overloading of the network and the related facilities [1,2]. This is an effect of replacing biologically active surfaces with water-tight surfaces $[3,4]$. Of no small importance are issues associated with climate change $[5,6]$, in particular intensified precipitation $[7,8]$. Therefore, in order to enable their proper functioning, it would be advisable to transform them into advanced sustainable drainage systems based on applying retention and control of wastewater flow within the system [9-11]. As a rule there are a few options for increasing retention capacity of the system. The choice of the most beneficial

* Corresponding author: kp@prz.edu.pl 
possibility should be based on an analysis of various criteria, most importantly including technical and economic factors. Due to their considerable dimensions and their complicated structure, retention facilities require high capital expenditures related to their construction [12]. Hence, it is advisable to apply such solutions which allow for minimizing their necessary cubic capacity, and consequently the capital expenditure, while ensuring the assumed level of operational security for sewage systems.

The purpose of the study is to perform functional hydraulic analysis of an innovative concept of Retention reservoir for rainwater and combined sewage during the specific phases of its functioning.

\section{Description of the concept of Retention reservoir for rainwater and combined sewage}

Retention reservoir for rainwater and combined sewage is an innovative solution which enables significant increase in retention capacity of sewage system without a necessity to change the positioning levels of sewers transporting wastewater along their flow route. The device in question has been presented and described in axonometric scheme (Fig. 1).

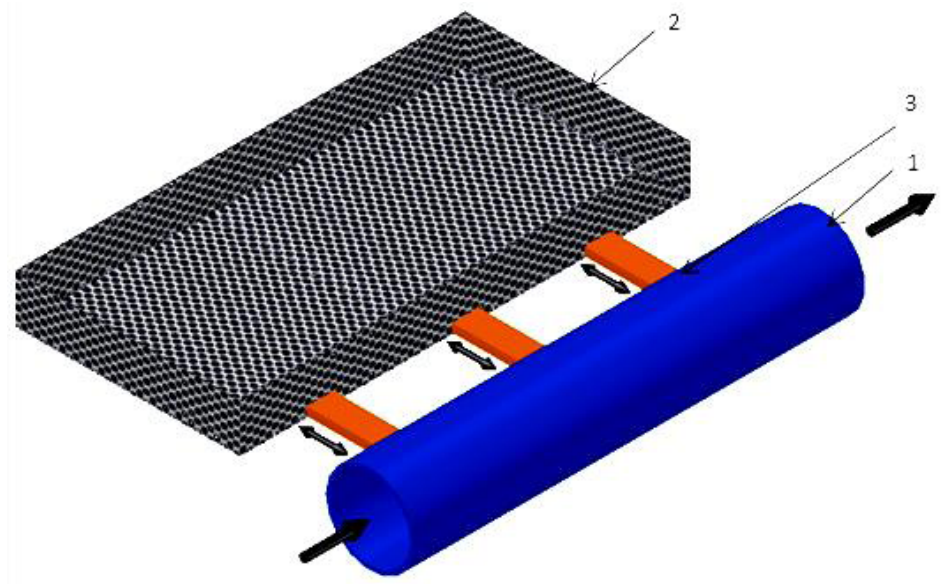

Fig. 1. Visualization of retention reservoir for rainwater and combined sewage: 1 - intercepting sewer, 2 - retention chamber, 3 - transit sewers.

Retention reservoir for rainwater and combined sewage has a retention chamber hydraulically connected with intercepting sewer via two-way transit sewers, whose bottom is located above the bottom of the intercepting sewer.

Designing a retention reservoir, which does not require varied levels of intercepting sewer positioning, increases the possibilities for staging of investment process and for expanding drainage systems as a given catchment area grows, without a need to reconstruct drain interceptors.

By increasing retention capacity of a sewage system it is possible to significantly reduce capital expenditures required by construction or modernization of such sewage system. Additionally, the invention may be applied both in existing and in newly designed retention facilities.

In specific cases, it is possible to increase volumetric flow rate of sewage passing to the reservoir chamber, by applying suitably shaped impounding structures.

An important aspect of the presented solution is the bottom of retention chamber which should be positioned above the bottom of the intercepting sewer, because this enables redirecting wastewater back to the sewage system. However, if part of rainwater were to be 
subjected to a process of infiltration through the soil, it would be possible to lower positioning of the reservoir bottom in relation to the intercepting sewer.

\section{Dimensioning of Retention reservoir for rainwater and combined sewage}

The use of this solution in engineering practice is associated with the adoption of appropriate procedures for its dimensioning. Figure 2 shows the dimensioning algorithm of retention reservoir for rainwater and combined sewage.

Dimensioning of retention reservoir for rainwater and combined sewage

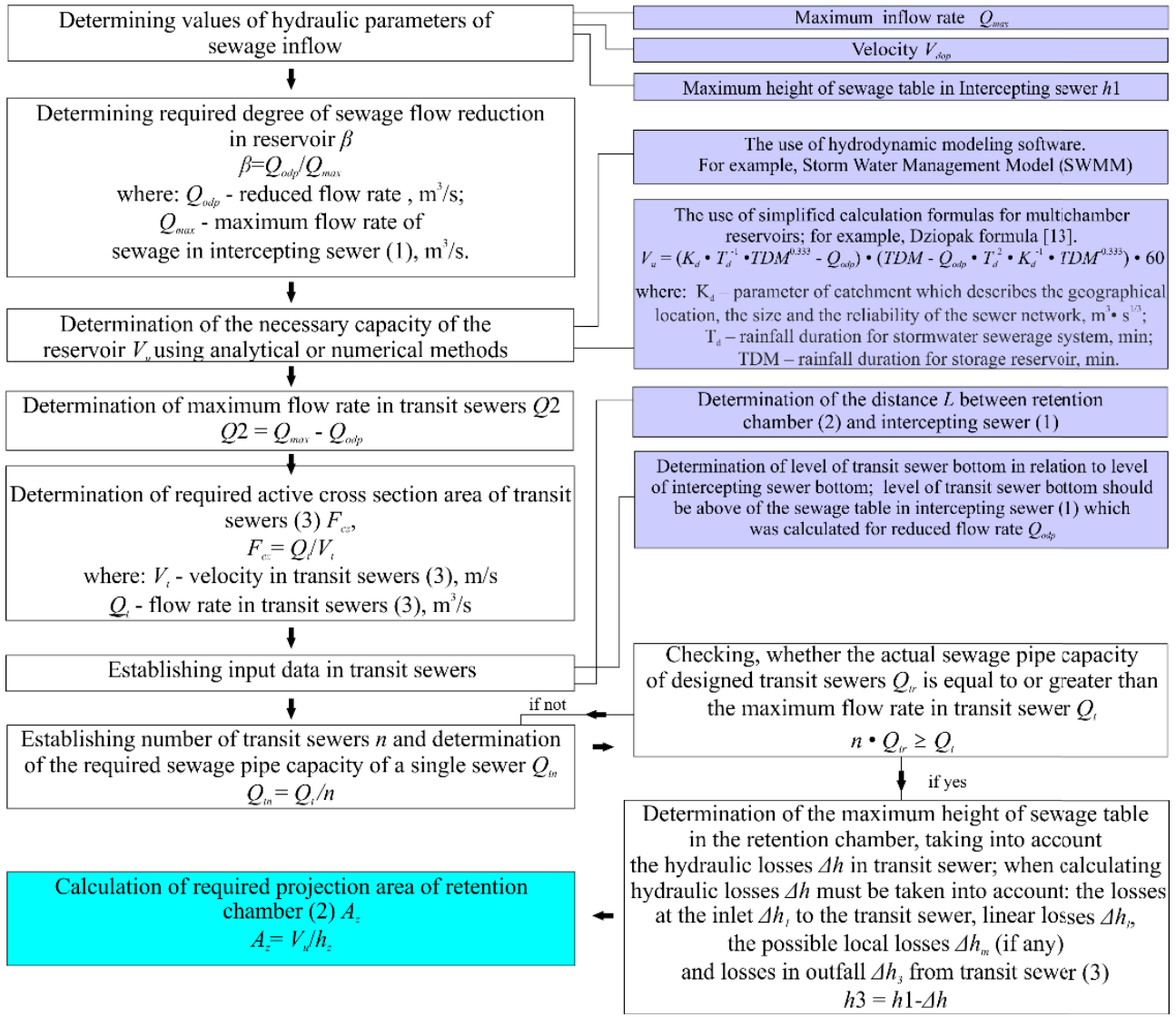

Fig. 2. The dimensioning algorithm of retention reservoir for rainwater and combined sewage.

The developed algorithm (Fig. 2) contains the procedure for dimensioning the individual components of retention reservoir for rainwater and combined sewage. A Particularly important element of this procedure is to determine the input parameters for the calculation i.e. flow rate in intercepting sewer, reduced flow rate, distances between intercepting sewer and the retention chamber, and the height of sewage table in the intercepting sewer for reduced flow rate. The issue of determining the hydraulic losses in the transit sewer is also important. They affect the maximum height of sewage table in the retention chamber. Use of the presented algorithm allow to design a retention tank for rainwater and sewage in combination. 


\section{Functional phases of Retention reservoir for rainwater and combined sewage}

Hydraulic analysis performed during the study examined operation of Retention reservoir for rainwater and combined sewage at the specific stages of its filling during rainfall. Schematic section of the reservoir is shown in Figure 3, which also presents outline of wastewater flow.

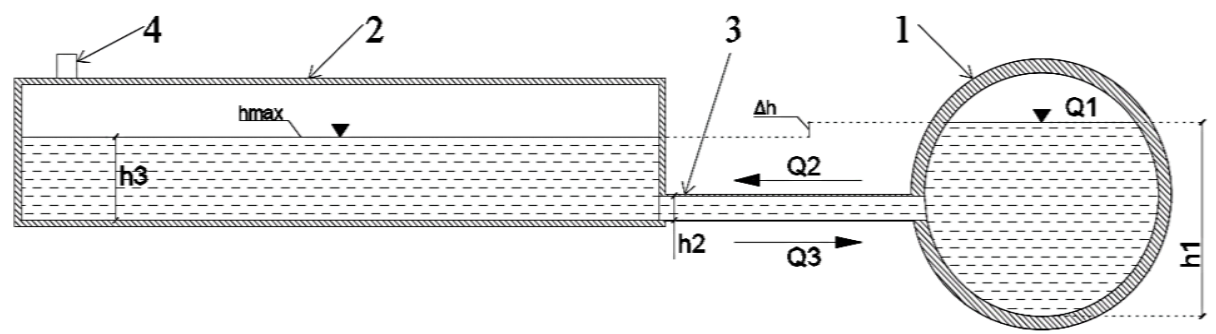

Fig. 3. Longitudinal section of retention reservoir with highly efficient hydraulic system: 1 - intercepting sewer, 2 - retention chamber, 3 - transit sewers, 4 - ventilation

h1 - level of wastewater in intercepting sewer, h2 - level of wastewater in transit sewer, h3 - level of wastewater in retention chamber of the reservoir, $\Delta \mathrm{h}$ - hydraulic losses in transit sewers,

Q1 - volumetric flow rate of wastewater in intercepting sewer, Q2 - volumetric flow rate of wastewater reaching retention chamber, Q3 - volumetric flow rate of wastewater leaving retention chamber.

\subsection{Functional Phase I of the solution}

The first functional phase of the installation, at the start of rainfall, is shown in Fig. 4. Because of the low flow rate in intercepting sewer (1), rainwater is not distributed between transit sewers (3). The system operates like conventional storm water drainage.

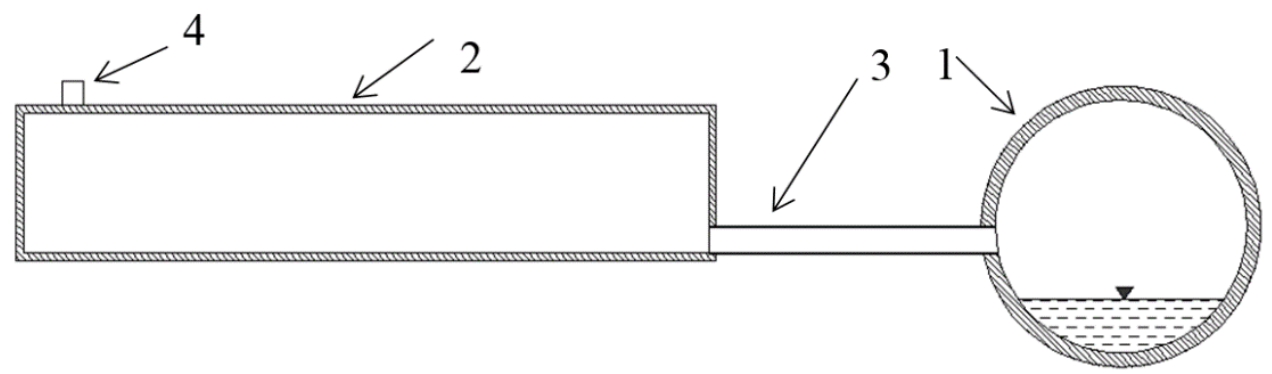

Fig. 4. Phase I of the reservoir operation.

- Boundary conditions in terms of high of fluid: h1.1 $>0, \mathrm{~h} 2.1=0, \mathrm{~h} 3.1=0$.

- Boundary conditions in terms of flow rate: $\mathrm{Q} 1.1>0, \mathrm{Q} 2.1=0, \mathrm{Q} 3.1=0$.

\subsection{Functional Phase II of the solution}

The second phase, shown in Fig. 5, reflects the situation when increased volumetric flow rate leads to accumulation of wastewater in sewer (1), up to the bottom of transit sewers (3), yet still does not induce their operation. 


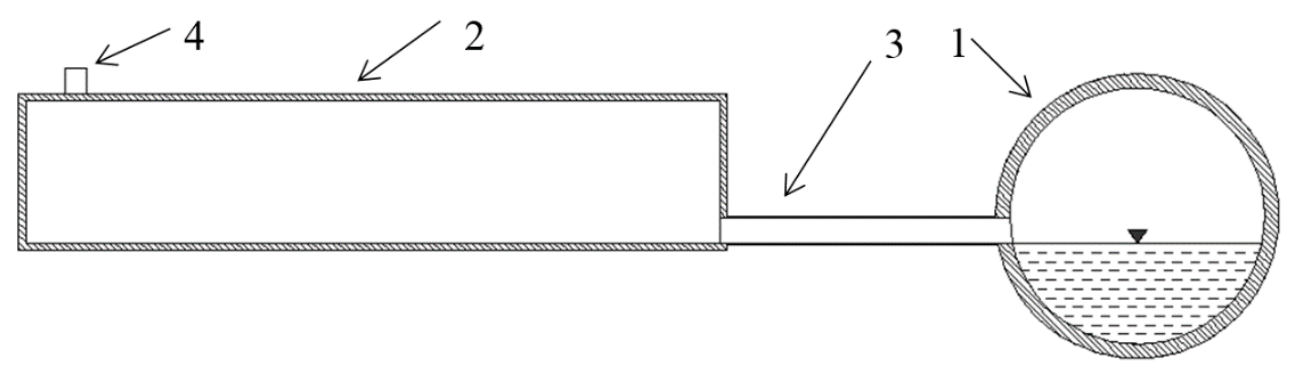

Fig. 5. Phase II of the reservoir operation.

- Boundary conditions in terms of high of fluid: h1.2 $>0, \mathrm{~h} 1.2>\mathrm{h} 1.1, \mathrm{~h} 2.2=0, \mathrm{~h} 3.2=0$.

- Boundary conditions in terms of flow rate: Q1.2 >0, Q1.2 $>$ Q1.1, Q2.2 =0, Q3.2 = 0 .

\subsection{Functional Phase III of the solution}

During the third phase, shown in Fig. 6, the level of wastewater is higher than the level of the base of transit sewers (3). During this phase, the volume of wastewater above the bottom of transit sewers (3) is transported via sewers to the reservoir accumulation chamber (2). Here, the volumetric flow rate is divided into rainwater directed via intercepting sewer (1) to the receiving body and rainwater carried via transit sewers (3) into retention reservoir (2). This is when the solution in question starts functioning; this results in increased sewer retention capacity of the section along which reservoir (2) is located and it enables significant reduction in the rate of flow along the intercepting sewer 1 further on to the system located downstream, or to the receiving body.

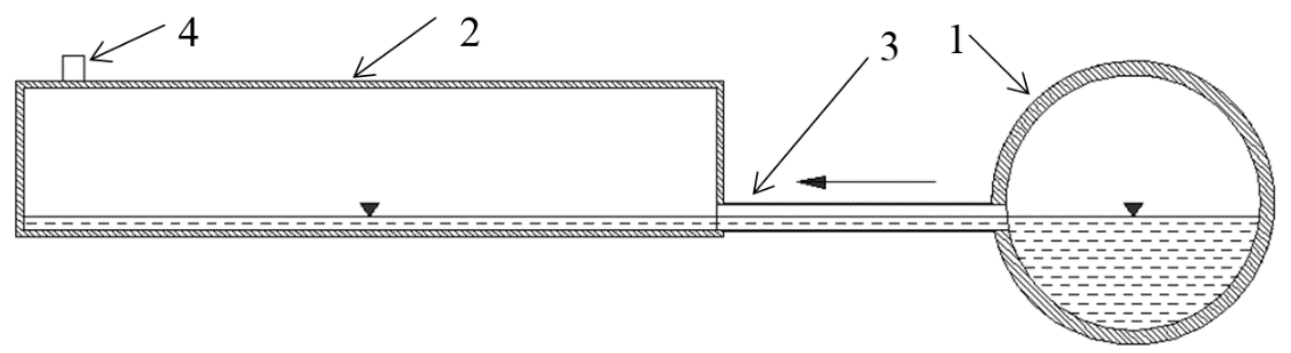

Fig. 6. Phase III of the reservoir operation.

- Boundary conditions in terms of high of fluid: h1.3 $>0$, h1.3 $>$ h1.2>h1.1, h2.3 $>0$, $\mathrm{h} 3.3>0$.

- Boundary conditions in terms of flow rate: Q1.3 > 0, Q1.3 > Q1.2 > Q1.1, Q2.3>0, $\mathrm{Q} 3.3=0$.

\subsection{Functional Phase IV of the solution}

The fourth functional phase of the invention, shown in Fig. 7, is the next and final stage of filling in the reservoir. During this phase, rainwater transported via transit sewer (3) leads to maximum accumulation resulting in its pressure-based functioning. Further filling of reservoir (2), and alignment of liquid levels in sewer (1) and reservoir (2) are enabled by efficiently operating ventilation (9). 


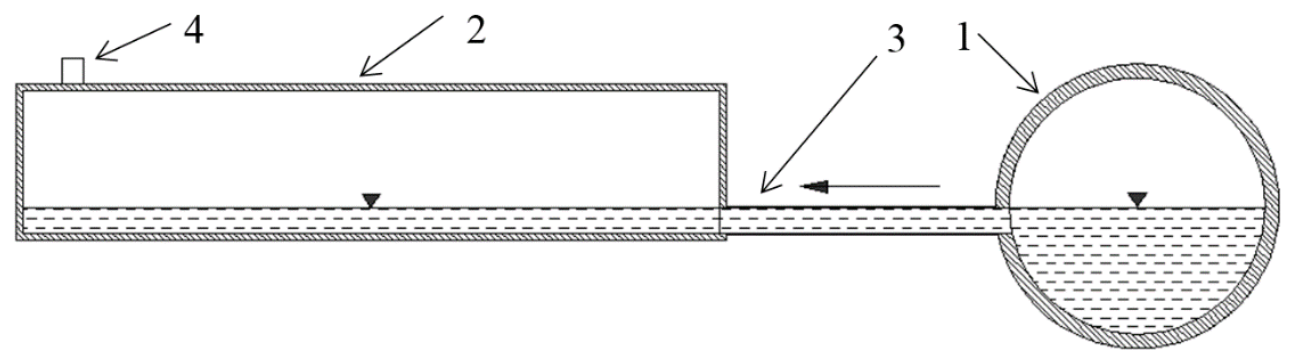

Fig. 7. Phase IV of the reservoir operation.

- Boundary conditions in terms of high of fluid: h1.4 $>0$, h1.4 $>$ h1.3 $>$ h1.2 $>$ h1.1, h2.4 $>0, \mathrm{~h} 2.4>\mathrm{h} 2.3, \mathrm{~h} 3.4>0, \mathrm{~h} 3.4>\mathrm{h} 3.3$.

- Boundary conditions in terms of flow rate: Q1.4 > 0, Q1.4 > Q1.3 > Q1.2 > Q1.1, $\mathrm{Q} 2.4>0$, Q2.4 > Q2.3, Q3.3 = 0 .

\subsection{Functional Phase $\mathrm{V}$ of the solution}

The fifth phase of the invention operation, as shown in Fig. 8, is the final stage of the process. As a result of the increased flow rate in transit sewer (3), the reservoir is filled in and the level of wastewater accumulated in it reaches the maximum design capacity $h_{\max }$. In the case of rainfalls exceeding critical parameters, for which the system is designed, rainwater may be released from the system in a controlled manner in retention reservoir (2), rather than at the location of intercepting sewer (1).

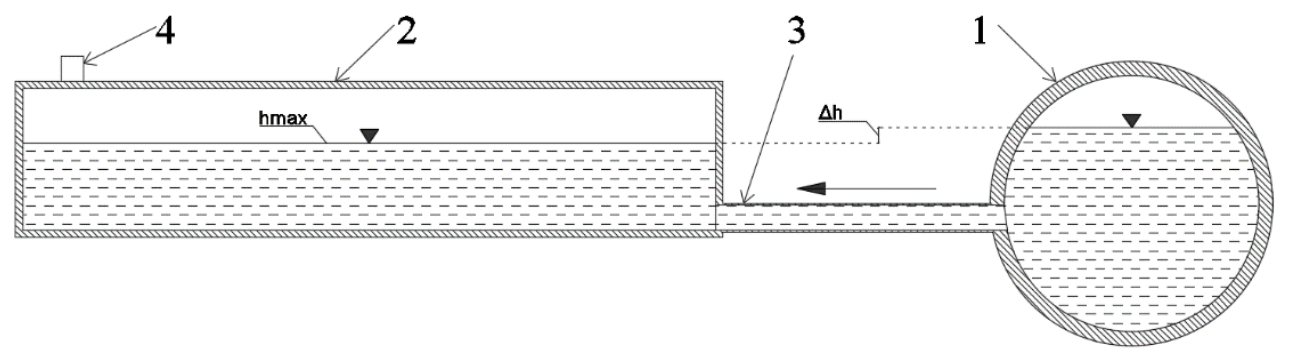

Fig. 8. Phase V of the reservoir operation.

- Boundary conditions in terms of high of fluid: h1.5 $>0, \mathrm{~h} 1.5>\mathrm{h} 1.4>\mathrm{h} 1.3>\mathrm{h} 1.2>\mathrm{h} 1.1$, $\mathrm{h} 2.5>0, \mathrm{~h} 2.5=\mathrm{h} 2.4, \mathrm{~h} 3.5>0, \mathrm{~h} 3.5>\mathrm{h} 3.4>\mathrm{h} 3.3$.

- Boundary conditions in terms of flow rate: Q1.5 $>0$, Q1.5 $>$ Q1.4 $>$ Q1.3 $>$ Q1.2 $>$ $\mathrm{Q} 1.1, \mathrm{Q} 2.5>0$, Q2.5 > Q2.4> Q2.3, Q3.5 = 0 .

\subsection{Functional Phase VI of the solution}

During phase 6, shown in Fig. 9, reservoir (2) is emptied. After rainfall stops, the level of rainwater in sewer system (1) gradually decreases. As a result, the same transit sewers 3, which during the previous phases led rainwater towards reservoir (2), now carry the rainwater back to intercepting sewer (1). This is enabled by the construction of transit sewers (3) running downward to intercepting sewer (1). 


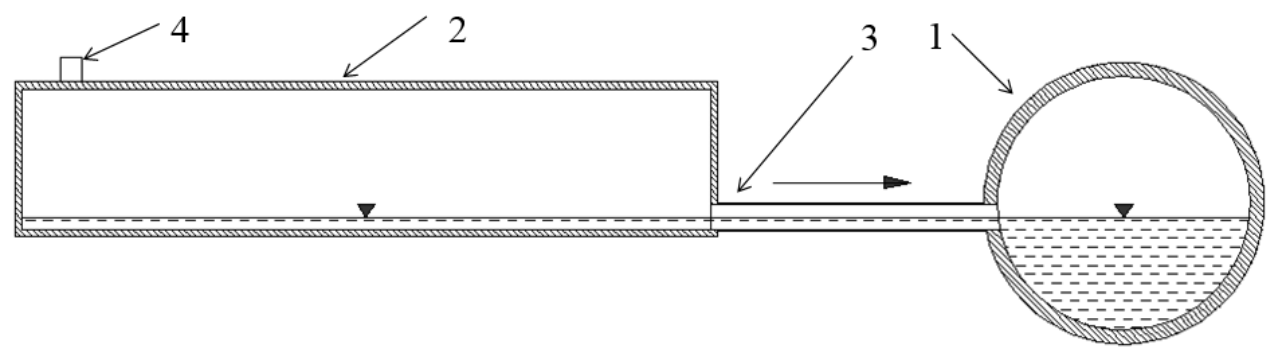

Fig. 9. Phase VI of the reservoir operation.

- Boundary conditions in terms of high of fluid: h1.6 $>0$, h1. $6<\mathrm{h} 1.4<\mathrm{h} 1.5, \mathrm{~h} 2.6>0$, $\mathrm{h} 2.6<\mathrm{h} 2.5, \mathrm{~h} 3.6>0, \mathrm{~h} 3.6<\mathrm{h} 3.4<\mathrm{h} 3.5$.

- Boundary conditions in terms of flow rate: Q1.6 $>0$, Q1.6 $<$ Q1.3 $<$ Q1.4 $<$ Q1.5, Q2.6=0, Q3.6 > 0 .

\subsection{Functional Phase VII of the solution}

The final seventh phase of reservoir operation is presented in Fig. 10. At this stage, level of rainwater in intercepting sewer (1) is lower than the level of the bottom supports in reservoir (2), as well as the lowest positioning of transit sewer (3). During this phase the reservoir is completely emptied.

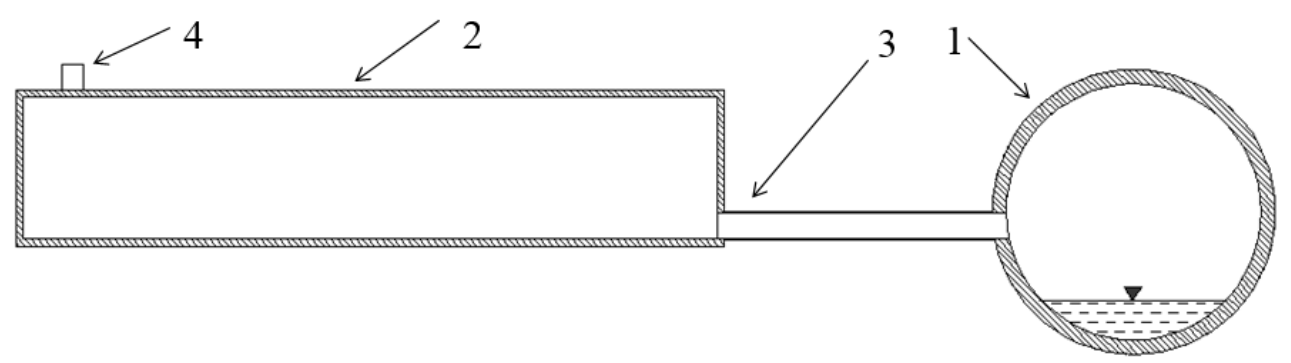

Fig. 10. Phase VII of the reservoir operation.

- Boundary conditions in terms of high of fluid: h1.7 $>0, \mathrm{~h} 2.7=0, \mathrm{~h} 3.7=0$.

- Boundary conditions in terms of flow rate: Q1.1 > 7, Q2.7 = 0, Q3.7 = 0.

\section{Summary and final conclusions}

The hydraulic model of Retention reservoir for rainwater and combined sewage shows that by applying this solution it is possible to significantly increase retention capacity of a sewage system. Its strengths most notably include the possibility to deposit excess rainwater or combined sewage in the reservoir retention chamber, without a necessity to lower its bottom in relation to the bottom of intercepting sewer. This is particularly important in existing drainage systems where due to the construction of conventional retention reservoirs it is frequently necessary to use pumping devices in order to increase the level of wastewater. Application of the solution in question in existing sewage systems makes it possible to ensure high standard of drainage and to improve hydraulic security of the system. 
Research carried out in the publication led to the following conclusions:

- filling of retention chamber occurs after obtaining the appropriate level of sewage table in the intercepting sewer. Thus, the solution can be used in existing sewage systems, in which there are periodic hydraulic overload,

- the procedure for reservoir dimensioning should include issue of determine the hydraulic losses in the transit sewers, which have an influence on maximum level of sewage table in retention chamber,

- in case of a small flow rate of sewage in intercepting sewer the retention chamber does not function. Therefore installing additional flow regulators in the intercepting sewer between transit sewers allow to force the inflow to retention chamber.

Further research related to the findings discussed in this article will include physical modeling and CFD comparison. Development of these models enable further analysis of the reservoir in a different conditions of sewage inflow.

\section{References}

1. M. Starzec, J. Dziopak, M.I. Alexeev, Water and Ecology 1, $41-50$ (2015)

2. A. Stec, S. Kordana, Resour. Conserv. Recy. 105, 84-94 (2015)

3. M. Zeleňáková, G. Markovič, D. Kaposztásová, Z. Vranayová, Procedia Engineering 89, 1515-1521 (2014)

4. T.D. Fletcher, H. Andrieu, P. Hamel, Adv. Water Resour. 51, 261-279 (2013)

5. D. Słyś, S. Kordana, Energ. Buildings 71, 1-11 (2014)

6. S. Kordana, D. Słyś, J. Dziopak, J. Clean. Prod. 82, 58-69 (2014)

7. K. Pochwat, D. Słyś, J. Dziopak, Gaz Woda i Technika Sanitarna 7, 269-272 (2013)

8. A. Kotowski, B. Kaźmierczak, J Hydrometeorol 14, 1958-1965 (2013)

9. K.B. Pochwat, JCEEA 63(2/II), 351-358 (2016)

10. Y.J. Chen, P. Cowling, F. Polack, S. Remde, P. Mourdjis, Eur. J. Oper. Res. 257, 494-510 (2017)

11. B.R.T. Vilane, E.J. Mwendera, Afr. J. Agric. Res. 6, 1313-1321 (2011)

12. Y. Kim, T. Kim, H. Park, M. Han, KSCE J. Civ. Eng. 19, 1585-1590 (2015)

13. Dziopak J. Multi-chamber storage reservoirs in the sewerage system (Czestochowa, 1997) 